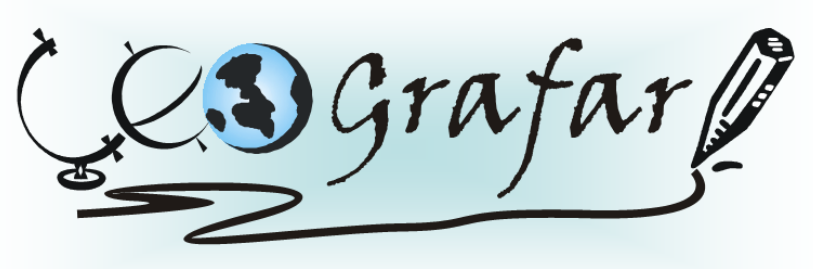

Revista Eletrônica do Programa de Pós-Graduação em Geografia - UFPR

\title{
POLARIZAÇÃO E DISPERSÃO INDUSTRIAL NAS MICRORREGIÕES DO SUL DO BRASIL
}

\author{
SANDRA CRISTIANA KLEINSCHMITT ${ }^{1}$ \\ JANDIR FERRERA DE LIMA ${ }^{2}$
}

\begin{abstract}
RESUMO
O objetivo deste artigo é analisar a polarização industrial nas microrregiões da Região Sul do Brasil, entre os anos 1991 e 2000. Para isto foi constituída uma metodologia específica, baseada na aplicação da análise fatorial, para explicar o perfil da polarização industrial. Este procedimento identificou as microrregiões que mais concentraram indústrias. Os resultados demonstraram uma reestruturação espacial da industrialização, com a formação de novos espaços industriais que provocam um novo perfil de concentração industrial.
\end{abstract}

Palavras-chave: Geoeconomia, reestruturação espacial, economia brasileira, economia regional, desenvolvimento regional.

\section{POLARIZATION AND DISPERSION OF INDUSTRY IN THE REGIONS OF THE SOUTH BRAZIL}

\begin{abstract}
This article aims to examine the industrial polarization in the internal regions of South Brazil, between the years 1991 and 2000. For this was set a specific methodology, based on the factor analysis to explain the profile of industrial polarization. This procedure identified those areas that more concentrated industries. The results showed a spatial restructuring of industrialization, with the formation of new sites that cause a kind of new concentration.
\end{abstract}

Keywords: Economics geography, spatial organization, Brazilian economics, regional economics, regional development.

\footnotetext{
1 sandracristiana01@yahoo.com.br

2 jandirbr@yahoo.ca
} 


\section{INTRODUÇÃO}

O objetivo deste artigo é analisar a polarização industrial nas microrregiões dos Estados do Paraná, Santa Catarina e Rio Grande do Sul, localizados na Região Sul do Brasil, entre os anos 1991 e 2000. Esta análise tem como referência o trabalho pioneiro "Polarização e despolarização industrial no Brasil e no Rio Grande do Sul" de Souza (1990).

Em seu trabalho, Souza (1990) examinou a polarização industrial no Brasil a partir da década 1970. No seu estudo, o autor percebeu que até 1968 o Estado de São Paulo atraiu várias unidades industriais, porém sofreu um declínio entre 1970 e 1990. Paralelo a desconcentração paulista ocorreu o mesmo processo no Estado do Rio Grande do Sul. Neste, a desconcentração industrial foi favorável ao interior gaúcho em detrimento da Região Metropolitana de Porto Alegre. Esse fato ocorreu, em grande medida, devido aos incentivos fiscais concedidos pelas regiões periféricas, tornando o processo de despolarização precoce.

Como no Brasil a concentração e o crescimento industrial no espaço não ocorreram de maneira simultânea, Souza (1990) percebeu que o crescimento de um centro efetuar-se-ia em detrimento das regiões periféricas. Isto causaria efeitos regressivos e profundas desigualdades regionais, provocadas principalmente pelo Estado paulista, já que possuía amplo desenvolvimento de suas redes ferroviárias, rodoviárias e aéreas. Além disso, estava próximo ao Estado do Rio de Janeiro, o grande centro consumidor da época.

Todos os elementos citados geraram o fortalecimento da economia paulista, pois uma vez que, interligada com a Região Sul pela BR-116, a competitividade dos seus produtos aumentaram em relação aos produzidos no Sul do Brasil. Essa nova dinâmica reforçou o dinamismo do centro hegemônico e os efeitos regressivos nos centros periféricos fora da Região Sudeste.

Por isso, o processo de industrialização do Sudeste brasileiro teve dois tipos de estímulos: a produção de bens de exportação e a distribuição de parte do capital do setor de exportação, sob a forma de investimentos em infraestrutura e acumulação de capital, e em salários, fortalecendo o mercado interno. Diferente do Sudeste, as Regiões Norte, Sul e Centro-Oeste terão seu povoamento efetivo e o 
avanço da ocupação espacial somente a partir da segunda metade do século XX. Após 1970, um movimento inverso começa a se produzir na economia brasileira: a reversão da polarização do Sudeste em direção ao Sul. Este movimento não acontece por acaso. Segundo Fonseca Netto (2001), Martine e Diniz (1991), a reversão da polarização vai se produzir em três contextos: (1) A necessidade de expansão das empresas de transformação e serviços do Sudeste em direção aos novos espaços do país; (2) As políticas governamentais cujo objetivo era produzir externalidades positivas nas regiões periféricas, e; (3) O efeito das economias de aglomeração, engendradas pelas mesorregiões Metropolitanas de São Paulo e Rio de Janeiro após 1980.

Souza (1990) reforça o contexto das políticas governamentais, pois acredita que a despolarização industrial do Brasil no início da década 1970 decorreu devido aos incentivos fiscais como os programas federais da Superintendência do Desenvolvimento da Amazônia (SUDAM) e da Superintendência do Desenvolvimento do Nordeste (SUDENE), ao asfaltamento, duplicações e construções de BRs, constituídas como meio de facilitar o acesso aos lugares, bem como a expansão dos grandes centros e ao alto custo de seus terrenos. Além do incentivo governamental em transporte, energia e comunicação.

Considerando a atual situação das microrregiões dos Estados do Paraná, Santa Catarina e Rio Grande do Sul, o problema que se propõe a analisar é a hipótese da reversão da polarização dos centros econômicos em detrimento do interior desses Estados. Para analisar esta hipótese, analisam-se a quantidade de indústrias em cada microrregião, bem como o número de trabalhadores envolvidos neste ramo de atividade e sua respectiva renda média anual, o Produto Interno Bruto (PIB) per capita, o PIB industrial e a População Economicamente Ativa (PEA).

Para desenvolver a problemática proposta, o presente artigo foi dividido em cinco partes, incluindo esta introdução. Na segunda parte apresenta-se o referencial teórico. Na terceira parte apresentar-se-á a metodologia aplicada referente ao método de análise fatorial. No quarto item realiza-se uma análise dessa nova reestruturação espacial da indústria na Região Sul do Brasil. Na quinta parte estão apresentadas às conclusões. 


\section{POLARIZAÇÃO E A CONCENTRAÇÃO INDUSTRIAL NO BRASIL}

A teoria da polarização sustenta que o crescimento não ocorre em todos os lugares, mas manifesta em pontos ou pólos de crescimento, com formas, intensidades e efeitos terminais variados no conjunto da economia. Além disso, a polarização marca a "dominação" do espaço regional pela estrutura de transformação que tende a se concentrar em espaços específicos (PERROUX, 1964; 1967; 1982).

Segundo Rippel e Ferrera de Lima (2009), os elementos de dominação, inicialmente definidos por Perroux (1977) como "unidade dominante" seria uma indústria ou um complexo industrial, com uma influência assimétrica no espaço econômico. A idéia da "unidade dominante", dada a sua amplitude, sofreu uma série de refinamentos e mudanças, e numa versão mais recente se tornou conhecida como Teoria dos "Pólos de Crescimento".

Ferrera de Lima (2003) chama a atenção que se devem distinguir dois tipos de pólos: crescimento e desenvolvimento. O pólo de crescimento é ativo, pois produz a expansão industrial, mantendo o ritmo crescente das atividades, em contraste ao pólo de desenvolvimento, que apenas produz a expansão da indústria mediante condições especiais. A dominação se dá através da ação de uma unidade motriz, que pode ser simples ou complexa, composta por empresas ou indústrias, ou uma combinação delas, que exerce um efeito de atração sobre as demais unidades a ela relacionadas.

Perroux (1982) aperfeiçoou o conceito de unidade motriz, em substituição da unidade dominante. Para ele, uma empresa motriz pode estar geograficamente situada em um local de exploração da matéria-prima e seu mercado de bens e serviços estar localizado em outras regiões, dessa forma a empresa ou indústria estará completamente "deslocalizada" em relação ao seu mercado de bens e serviços (ex.: indústria de mineração).

Em outra vertente de análise, Krugman (1991) afirma que o fortalecimento da polarização é o resultado da associação entre baixos custos de transporte, de relações interindustriais de cooperação e de concorrência inter-regional. As regiões periféricas aliam custos expressivos de transporte com uma relação de dependência 
nas atividades de transformação e serviços. Isso faz com que as regiões periféricas tenham um custo maior de produção e distribuição aliada a problemas com retorno de escala. Custos moderados de produção em conjunto a retornos de escala e custos de serviços pouco significativos estimulam a concentração geográfica dos agentes econômicos, e, conseqüentemente, no perfil da localização das atividades produtivas e na organização do espaço econômico. A estrutura dos custos e os rendimentos crescentes têm um papel decisivo na integração espacial da economia e na formação de pólos econômicos.

Para Ferrera de Lima (2003), a dependência sugerida por Krugman (1991) se reflete na concentração das atividades produtivas. A concentração e a dominação oriunda da dependência demonstram a existência de um centro e de uma periferia. A periferia é composta de vários espaços que gravitam no campo de influência econômica e política do pólo ou centro. Nesse sentido, as áreas metropolitanas constituem exemplo muito claro do conceito de região polarizada. $E$ isso se aplica ao caso brasileiro, pois, segundo Diniz (1995), até 1970, o Brasil vivenciou um constante processo de concentração industrial nos Estados de São Paulo e Rio de Janeiro. Em 1970, já num estágio final do processo de concentração, o Estado de São Paulo participava com 39\% da renda nacional e o Rio de Janeiro com 16\%, totalizando $55 \%$ de concentração da renda na Região Sudeste.

A partir desse período, até aproximadamente 1985 houve clara tendência à desconcentração geográfica da produção industrial no Brasil e também no Estado de São Paulo. Neste período, deu-se início ao movimento de reversão da polarização e de desconcentração industrial para várias regiões do país. Vários elementos contribuíram para esta reversão, entre eles: a crise da década de 1980; pelo movimento da fronteira agropecuária no Sul do Brasil e, depois, em direção às regiões Centro-Oeste e Norte e o cerrados do Nordeste; pela reconcentração de atividades em setores tecnologicamente desenvolvidos; pela redução de investimentos estatais em infra-estrutura; e, pela pequena dimensão do mercado interno. Assim, desenvolveu-se um "Polígono Industrial" constituído pelos municípios de Belo Horizonte - Uberlândia - Londrina/Maringá - Porto Alegre - Florianópolis São José dos Campos - Belo Horizonte (DINIZ, 1995).

Segundo Pacheco (1999), apesar da clara tendência à desconcentração, o Estado de São Paulo continuava concentrando os segmentos mais dinâmicos das 
indústrias. Além disso, em paralelo à desconcentração da indústria decorrente no Brasil, São Paulo vivenciava um processo de rearranjo espacial interno de localização industrial.

No caso da Região Sul, em 1970 os níveis de produtividade industrial eram baixos, ocupando o segundo lugar em comparação com as demais regiões. Já entre 1970 até 1987, o crescimento foi notável, com aproximação da média nacional de produtividade industrial no ano de 1987, mantendo o patamar até 1991. Em termos setoriais, os bens de consumo não duráveis são os produtos que mais se aproximaram da média nacional (AZZONI; FERREIRA, 1997).

Para o Estado do Rio Grande do Sul, três aspectos podem ter ocasionado este crescimento, tais como a expansão agrícola e seus efeitos multiplicadores sobre as agroindústrias a montante e sobre as processadoras; o crescimento da indústria de bens de capital e de consumo duráveis na região Metropolitana de Porto Alegre-Caxias; e, o crescimento da indústria de couro e calçados. O Estado de Santa Catarina foi beneficiado pela dupla base industrial. À Oeste pela indústria frigorífica especializada em aves e suínos e do outro lado, a tradicional região de Blumenau-Joinville, com produção diversificada de têxteis, instrumentos musicais, motores e fundidos. A expansão industrial desse Estado sustentou-se basicamente no empresariado local. Já o Estado do Paraná, que tradicionalmente tinha suas indústrias ligadas ao complexo da madeira, teve grande expansão das agroindústrias processadoras devido à qualidade das terras e da expansão da produção agrícola (DINIZ, 1995). Na mesma linha de análise, Ruiz e Domingues (2005) identificaram um corredor industrial na Região Sul que interliga as Regiões de Londrina à Região Metropolitana de Curitiba, Joinville, Blumenau, Caxias do Sul, até a Região Metropolitana de Porto Alegre. Somente o Oeste do Paraná sairia deste corredor.

A partir da década de 1990, estudos de Diniz (1995) e Diniz e Crocco (1994) apontaram um processo de reconcentração nas áreas mais desenvolvidas do país. Os autores afirmavam que as principais razões para a re-localização estariam associadas à concessão de benefícios fiscais, à proximidade de mercado, ao custo da mão-de-obra e às vantagens locacionais específicas, tais como abundância de recursos naturais, avaliação dos novos mercados e aos investimentos em infraestrutura. O novo perfil de aglomeração das áreas mais dinâmicas ocorreu nas 
capitais ou nas cidades de porte médio, na grande faixa que vai da região central de Minas ao nordeste do Rio Grande do Sul, incluído o interior de São Paulo.

Azzoni e Ferreira (1997) analisaram a competitividade das regiões brasileiras referentes ao setor da indústria de transformação. Os resultados obtidos indicaram um aumento da concentração industrial no Estado de São Paulo nos últimos dez anos, bem como um ganho considerável na participação de Minas Gerais, ao passo em que as demais regiões perderam participação relativa. Para os autores, isto reforça a idéia de que a área industrial principal do Brasil estaria ampliando a sua competitividade, com o seu núcleo espraiando-se para áreas vizinhas, transbordando de São Paulo para os Estados limítrofes, com exceção do Rio de Janeiro.

Ao final do século XX a tendência de desconcentração industrial do Sudeste em direção as regiões periféricas do Brasil se fortaleceu. Apesar dessa tendência, a Região Sudeste ainda possui a economia mais diversificada do Brasil e que concentra o maior potencial de mercado (AZZONI; CAPELATO, 1996). Diferente da Região Sudeste, a Região Sul terminou o século XX aumentando seu nível de especialização do emprego formal nos setores de Comércio e Indústria, enquanto o Centro-Oeste se diversificava. $O$ fortalecimento da especialização não significa um retrocesso no processo de desenvolvimento regional, mas uma particularidade que deve ser mais bem estudada. Assim, as regiões brasileiras, com exceção do Sul do país, tenderam a convergir em direção à diversificação da distribuição do emprego formal entre os setores econômicos.

Segundo Fonseca e Peris (2002) a desconcentração industrial de São Paulo não tem direcionamento somente para o interior do Estado, ela também atinge outros Estados, como é o caso do Paraná, devido a sua proximidade. Ao mesmo tempo, existe a tendência contínua à concentração espacial da indústria paranaense. A Região Metropolitana de Curitiba elevou sua participação no valor adicionado industrial, de 30,3\%, em 1974, para, 58,3\% em 1994. Assim a dinâmica da industrialização da Região Metropolitana de Curitiba, esteve vinculada ao processo de desconcentração da indústria de São Paulo. Já a dinâmica econômica do interior do Estado do Paraná não se encontra vinculada ao mesmo processo de industrialização da capital. 
Para Pacheco (1999), essas mudanças mostram sensível alteração na dimensão espacial do desenvolvimento brasileiro, mostrando uma possível continuidade da desconcentração das últimas décadas que foram acompanhadas pelo aumento da heterogeneidade interna das regiões brasileiras, com o surgimento de "ilhas" de produtividade em quase todas as regiões, além do crescimento relativo maior das "antigas periferias" nacionais e importância maior do conjunto das cidades médias perante as áreas metropolitanas A própria tendência locacional, sobretudo em São Paulo, tendeu a favorecer municípios de porte médio, dotados de infraestrutura e próximos à malha de transportes, mas distantes dos problemas crônicos das grandes cidades. No entanto, a perda de peso relativo da indústria metropolitana está muito longe de qualquer processo de desindustrialização.

Dessa forma, os autores mostram uma tendência de reestruturação espacial da economia, dando forma a uma nova organização espacial da indústria a partir dos anos 1990.

\section{METODOLOGIA DA ANÁLISE}

As variáveis referentes a esta análise são a quantidade de indústrias em cada microrregião, bem como o número de trabalhadores envolvidos neste ramo de atividade e sua respectiva renda média anual, o Produto Interno Bruto (PIB) industrial e PIB da microrregião e a População Economicamente Ativa (PEA). As fontes de dados utilizadas na análise são a Relação Anual de Informações Sociais (RAIS) e o Instituto Brasileiro de Geografia e Estatística (IBGE), nos anos 1991 e 2000. Com exceção das variáveis: PIB industrial e PIB da microrregião, pois teve o ano 1996 como base. Cada variável representa os dois anos de análise, respectivamente 1991 e 2000, com exceção das duas já citadas (1996 e 2000).

A análise foi efetuada a partir da análise fatorial, que explica 0 comportamento de um conjunto de variáveis reduzindo-as a um número menor de fatores, resumindo um conjunto de variáveis a um conjunto de fatores (HOFFMANN, 1999). No geral, o número de fatores torna-se bem menor em relação ao número de variáveis observadas.

A análise fatorial será utilizada para obter medidas do grau de concentração industrial nas microrregiões analisadas. Pretende-se, então, obter de maneira 
simples um número pequeno de fatores que indicam primeiramente o grau de concentração industrial existente, o que direciona esta análise, para os Componentes Principais. Desta forma, analisando 94 microrregiões do Sul do Brasil, a partir de um conjunto de seis indicadores de industrialização para cada período enfocado 1991-1996 e 2000, define-se:

$$
\begin{aligned}
& \mathbf{X}_{1} \text { a matriz } 94 \text { × } 6 \text { para } 1991 \text { e } 1996 \text {; e, } \\
& \mathbf{X}_{2} \text { a matriz } 94 \text { × } 6 \text { para 2000; }
\end{aligned}
$$

Agregando-se as observações referentes aos dois anos e visando obter o grau de concentração industrial, definiu-se a matriz $188 \times 6$ :

$$
X=\left[\begin{array}{l}
X_{1} \\
X_{2}
\end{array}\right]
$$

Para obter o grau de evolução temporal do Fator de Componente Principal 1(FCP1), todas as 6 variáveis foram agregadas temporalmente, ou seja, formou-se uma única matriz de $188 \times 6$, com o valor das 6 variáveis de cada microrregião para o ano 1991 e/ou 1996 e seguida pelas 6 variáveis de cada microrregião para o ano 2000. Feito isso, a variabilidade das 6 variáveis nos dois períodos foi sumarizada no FCP1, obtendo-se daí a evolução de cada microrregião através da obtenção da diferença de industrialização para a mesma microrregião entre 1991 e 2000. Definindo-se:

$$
\text { Evolução (FCP1) = Microrregião X(2000) - Microrregião X(1991/1996) }
$$

Neste sentido, a presente análise realizar-se-á por meio da análise fatorial, com o objetivo de obter algumas medidas do grau de associação entre os indicadores de industrialização e o grau de concentração/desconcentração industrial existente nas microrregiões do Sul do Brasil. Com base nos procedimentos metodológicos e a partir dos dados constantes na matriz construída para esta 
análise, procedeu-se à análise fatorial pelo método de Componentes Principais usando o Data Analysis Software System (STATISTICA). O método dos componentes principais resume e organiza o padrão de correlação entre as variáveis, apontando um conjunto de variáveis que não são correlacionadas umas com as outras (SCREMIN, 2003).

\section{O GRAU DE CONCENTRAÇÃO INDUSTRIAL NAS MICRORREGIÕES: RESULTADOS E DISCUSSÕES}

A presente análise constatou, a partir da Análise Fatorial do Método de Componentes Principais, que o FCP1 explica 95,54\% da relação existente entre as 6 variáveis nos períodos 1991/1996 e 2000 e entre a variável híbrida que é o Fator 1. Nesse sentido, o Fator de Componente Principal 2 (FCP2) explica, somente, 1,83\%. Assim, optou-se por descartar o FCP2, pois sua porcentagem total é muito baixa. A escolha, então, pelo FCP1 é pela alta porcentagem total e pela inexistência de critérios para a escolha da quantidade de fatores necessários para a análise, conforme mostra a Tabela 1.

TABELA 1 - RAÍZES CARACTERÍSTICAS DA ANÁLISE DE COMPONENTES PRINCIPAIS

\begin{tabular}{lcc}
\hline \multicolumn{1}{c}{ Itens } & $\begin{array}{c}\text { Fator do Componente } \\
\text { Principal 1 }\end{array}$ & $\begin{array}{c}\text { Fator do Componente } \\
\text { Principal 2 }\end{array}$ \\
\hline Raízes Características & 11,46 & 0,22 \\
Porcentagem Total & $95,54 \%$ & $1,83 \%$ \\
Raízes Características acumuladas & 11,46 & 11,68 \\
Porcentagem total acumulada & $95,54 \%$ & $97,37 \%$ \\
\hline
\end{tabular}

FONTE: DADOS DA PESQUISA (2007)

As cargas fatoriais representam os coeficientes de correlação entre cada fator e cada uma das variáveis nos períodos 1991/1996 e 2000. Os fatores são extraídos na ordem do mais explicativo para o menos explicativo. Como todas as cargas fatoriais do FCP1 ficaram acima de $|0,95|$, em valor absoluto (destacados em negrito), pode-se verificar uma forte correlação entre todas as variáveis e entre o FCP1, conforme apresentados na Tabela 2. Entretanto, o mesmo não ocorre com o 
FCP2, cuja carga fatorial atingiu o máximo $|0,19|$, em valor absoluto, o que representa baixa correlação entre as variáveis.

TABELA 2 - CARGAS FATORIAIS NA ANÁLISE FATORIAL DOS INDICADORES DE INDUSTRIALIZAÇÃO NAS MICRORREGIÕES DO SUL DO BRASIL, NOS PERÍODO 1991/1996 E 2000

\begin{tabular}{llc}
\hline Variáveis & \multicolumn{1}{c}{ Variáveis } & Fator 1 \\
\hline Variável 1 & - Trabalhadores nas indústrias (1991) & $-\mathbf{0 . 9 8}$ \\
Variável 2 & - Renda média dos trabalhadores das indústrias (1991) & -0.99 \\
Variável 3 & - Quantidade de indústrias (1991) & -0.99 \\
Variável 4 & - PEA (1991) & $-\mathbf{0 . 9 7}$ \\
Variável 5 & - PIB industrial (1996) & -0.97 \\
Variável 6 & - PIB da Microrregião (1996) & $-\mathbf{0 . 9 8}$ \\
Variável 7 & - Trabalhadores nas indústrias (2000) & $-\mathbf{0 . 9 8}$ \\
Variável 8 & - Renda média dos trabalhadores das indústrias (2000) & $-\mathbf{0 . 9 9}$ \\
Variável 9 & - Quantidade de indústrias (2000) & $-\mathbf{0 . 9 7}$ \\
Variável 10 & - PEA (2000) & $-\mathbf{0 . 9 8}$ \\
Variável 11 & - PIB industrial (2000) & $-\mathbf{0 . 9 8}$ \\
Variável 12 & - PIB da Microrregião (2000) & $-\mathbf{0 . 9 5}$ \\
\hline
\end{tabular}

FONTE: DADOS DA PESQUISA (2007)

Verifica-se, assim, que a microrregião de Porto Alegre concentra grande parte das indústrias no Sul do Brasil nos anos 1991 e 2000, concentrando também, todas as outras variáveis consideradas nesta análise. A concentração industrial da microrregião de Porto Alegre é seguida pelas microrregiões de Curitiba, Caxias do Sul, Joinville e Blumenau. Neste sentido, percebe-se que essas cinco microrregiões formam uma espécie de corredor de desenvolvimento industrial no Sul do Brasil. No Paraná e no Rio Grande do Sul, esse corredor estimula um processo de fortalecimento de polarização territorial no restante desta região.

Ao contrário, no Estado de Santa Catarina as atividades produtivas são mais dispersas no espaço, em especial estimuladas pelas atividades do transporte e comunicação, comercial e de serviços que possuem um coeficiente de distribuição mais elevado. O Estado de Santa Catarina está fortalecendo a dispersão da indústria de transformação ao longo do seu território, a partir da convergência relativa da localização do emprego industrial (FERRERA DE LIMA et al., 2007).

De acordo com os resultados da pesquisa, apesar da microrregião de Porto Alegre reunir a maior parte das indústrias no Sul do Brasil, nos períodos analisados, a Microrregião de Curitiba foi a que mais concentrou essas no espaço. Ou seja, no 
ano 1991 a microrregião de Curitiba continha 5.117 indústrias e atraiu mais 1.335, totalizando 6.452 indústrias.

Outra microrregião que se destacou no processo de concentração industrial foi Apucarana, localizada no Norte do Paraná. Esta microrregião possuía baixa concentração de indústrias no espaço e, mesmo assim, foi à segunda microrregião do Estado e do Sul do Brasil a ser mais atrativa no período, saltando de 611 indústrias para 1.037 (RAIS, 2007).

Contudo, na microrregião de Porto Alegre a instalação de novas empresas não deixou de ocorrer, pois das 7.189 empresas que estavam localizadas naquela microrregião, outras 1.651 instalaram-se no local, totalizando 8.840 indústrias no ano 2000 (RAIS, 2007). Como se percebe, a microrregião não sofreu um processo de esvaziamento industrial, mas entrou numa nova fase de estabilização, ou seja, cresceu, mas não de forma tão intensiva como ocorria nos anos anteriores.

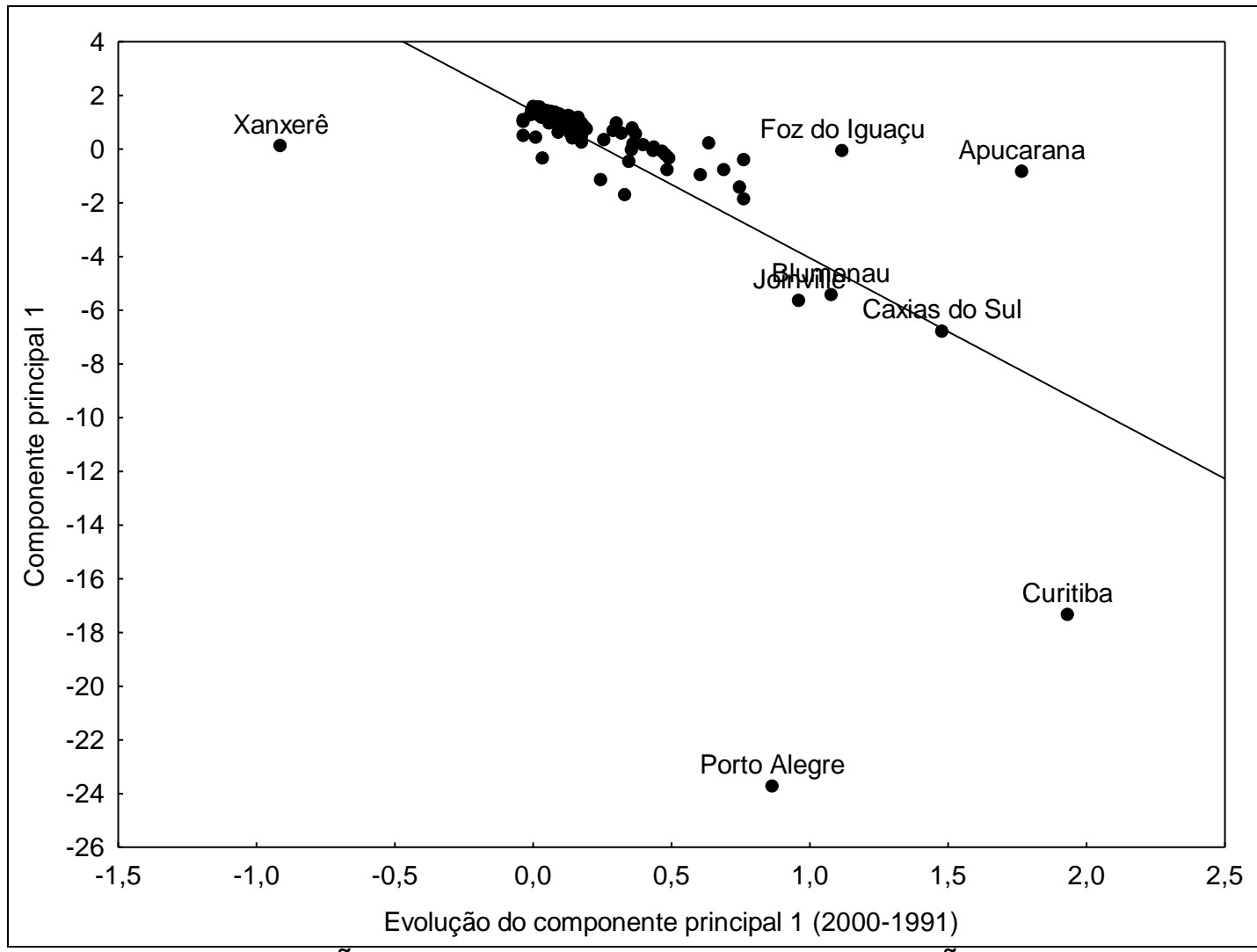

FIGURA 1 - EVOLUÇÃO DO GRAU DE CONCENTRAÇÃO INDUSTRIAL NAS MICRORREGIÕES ENTRE 1991/1996 E 2000

FONTE: DADOS DA PESQUISA (2007) 
A partir dos resultados da figura 1, percebe-se que a Região Sul do Brasil passa a vivenciar um rearranjo espacial da industrialização. Os lugares tradicionais, como a microrregião de Porto Alegre inicia um processo de atrofiamento no seu padrão de localização industrial, mas não de retrocesso industrial. Isto demonstra a configuração de novos espaços e novas frentes industriais e ocasionam uma "desconcentração concentrada" nos Estados sulinos, evidenciando uma nova fase de configuração do espaço industrial. Ou seja, a desconcentração ocorre dentro do espaço geográfico do Sul do Brasil, pois se espraia ao longo do seu território. De um lado isso fortalece as micro e mesorregiões do Sul, o que demonstra que o processo de desconcentração industrial é diferenciado espacialmente no Brasil. Ele tende em primeiro lugar a beneficiar de forma contigua os espaços localizados próximos das regiões mais ricas, para na sequência atingir os espaços mais eqüidistantes.

Se as mesorregiões metropolitanas perdem empregos industriais, as mesorregiões do interior ganham. Para Ferrera de Lima et al. (2007), essa característica é o reflexo do fortalecimento das agroindústrias, além das indústrias de alta tecnologia que se instalaram nas regiões Metropolitanas de Curitiba e Porto Alegre, no Nordeste Riograndense e Norte Catarinense.

Outro elemento a se destacar é que todos os três Estados do Sul do Brasil apresentam um arranjo específico do território industrial. No Estado do Paraná, conforme o figura 2, entre os anos 1991 a 2000 firmam-se três frentes industriais: 1) em torno das microrregiões de Curitiba e Ponta Grossa; 2) no Norte Pioneiro entre as Microrregiões de Londrina, Maringá e agora, também, Apucarana, e; 3) surge o Oeste do Paraná, com forte crescimento na microrregião de Foz do Iguaçu, principalmente, seguida pelas microrregiões de Toledo e Cascavel. O grau de concentração industrial das principais microrregiões do Estado do Paraná está exposto na figura 2. 


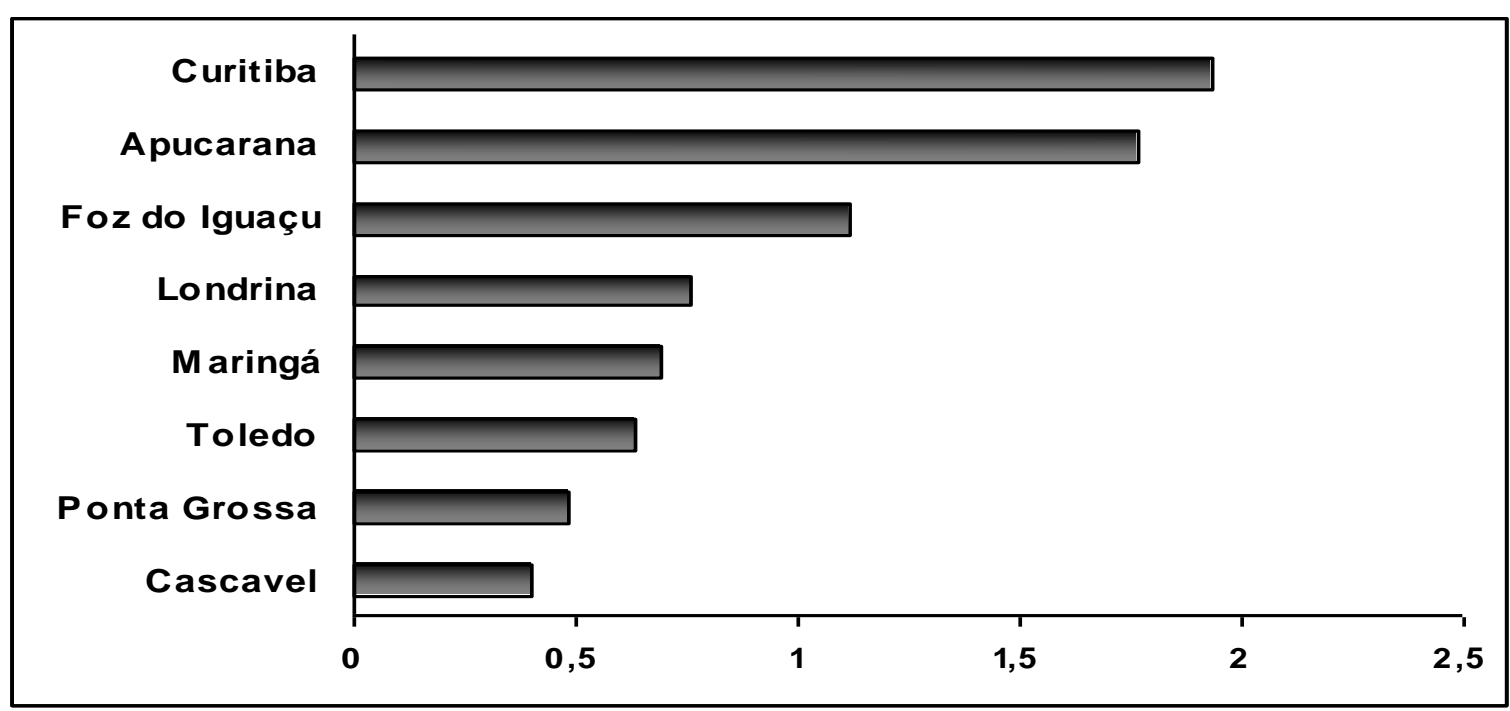

FIGURA 2 - GRAU DE CONCENTRAÇÃO INDUSTRIAL DAS PRINCIPAIS MICRORREGIÕES DO ESTADO DO PARANÁ, ENTRE OS ANOS 1991 E 2000 FONTE: DADOS DA PESQUISA (2007)

Entre os anos 1991 e 2000 ocorreu, principalmente, na microrregião de Curitiba, investimentos e incentivos governamentais para a atração de novas indústrias montadoras e de metal-mecânica. Esses incentivos fiscais facilitaram a entrada de diversas indústrias, dentre elas a Renault, a Volvo, etc., que ajudou no processo de atração de diversas outras indústrias do mesmo segmento, além de atrair fortes investimentos governamentais em infra-estrutura e redes de transporte, energia, comunicação, etc.

No Norte Pioneiro, destaca-se o crescimento da microrregião de Apucarana. Neste período a microrregião atraiu mais de 420 empresas, sendo a microrregião do interior do Estado do Paraná e também do Sul do Brasil que mais teve crescimento industrial entre os anos 1991 e 2000, com destaque para as agroindústrias Kowalski, Caramuru, Bungue, Mahpa e Corol. Além do crescimento das empresas ligadas diretamente ao agronegócio e ao processamento de grãos, a microrregião possui indústrias têxteis e um Arranjo Produtivo Local (APL) de Bonés, com capacidade atual para abastecer $50 \%$ do país.

Os fatores para essa grande atração industrial na microrregião de Apucarana são por ela estar localizada entre as microrregiões de Londrina e Maringá, e por localizar-se no entroncamento rodo-ferroviário do Centro-Norte do Paraná. Só no município de Apucarana cruzam-se duas rodovias federais, a BR-376 
(Rodovia do café) e a BR-369 (Rodovia Mello Peixoto), que corta todo o Estado do Paraná. Passam também pelo município duas rodovias estaduais a PR-444 e a PR170. O município também possui uma linha férrea e um aeroporto aberto somente a vôos para transporte de mercadorias e aeronaves particulares. Como conseqüência, torna-se geograficamente ponto ideal para o Mercosul e o caminho de ligação entre os grandes centros de consumo e produção.

A microrregião de Foz do Iguaçu destaca-se principalmente pela expansão do agronegócio entre os anos 1991 e 2000, com o surgimento de inúmeras agroindústrias, das cooperativas do processamento dos produtos agrícolas, tais como soja, mandioca, aves, suínos, e do setor moveleiro, localizadas, sobretudo, no município de Medianeira.

Muito mais que a configuração de três frentes industriais, percebe-se que das 15 microrregiões do Sul do Brasil que mais concentraram indústrias no espaço entre os anos 1991 e 2000, 10 estão localizadas no Estado do Paraná. Além disso, estas microrregiões estão próximas das microrregiões de Curitiba(1) e Ponta Grossa(2), no Norte em volta das microrregiões de Londrina(3), Maringá(4) e Apucarana(5), e, no Oeste, próximo das microrregiões de Cascavel(6), Toledo(7) e Foz do Iguaçu(8), configurando-se um processo de esvaziamento no Centro do Estado do Paraná, conforme visualizado no mapa 1. 


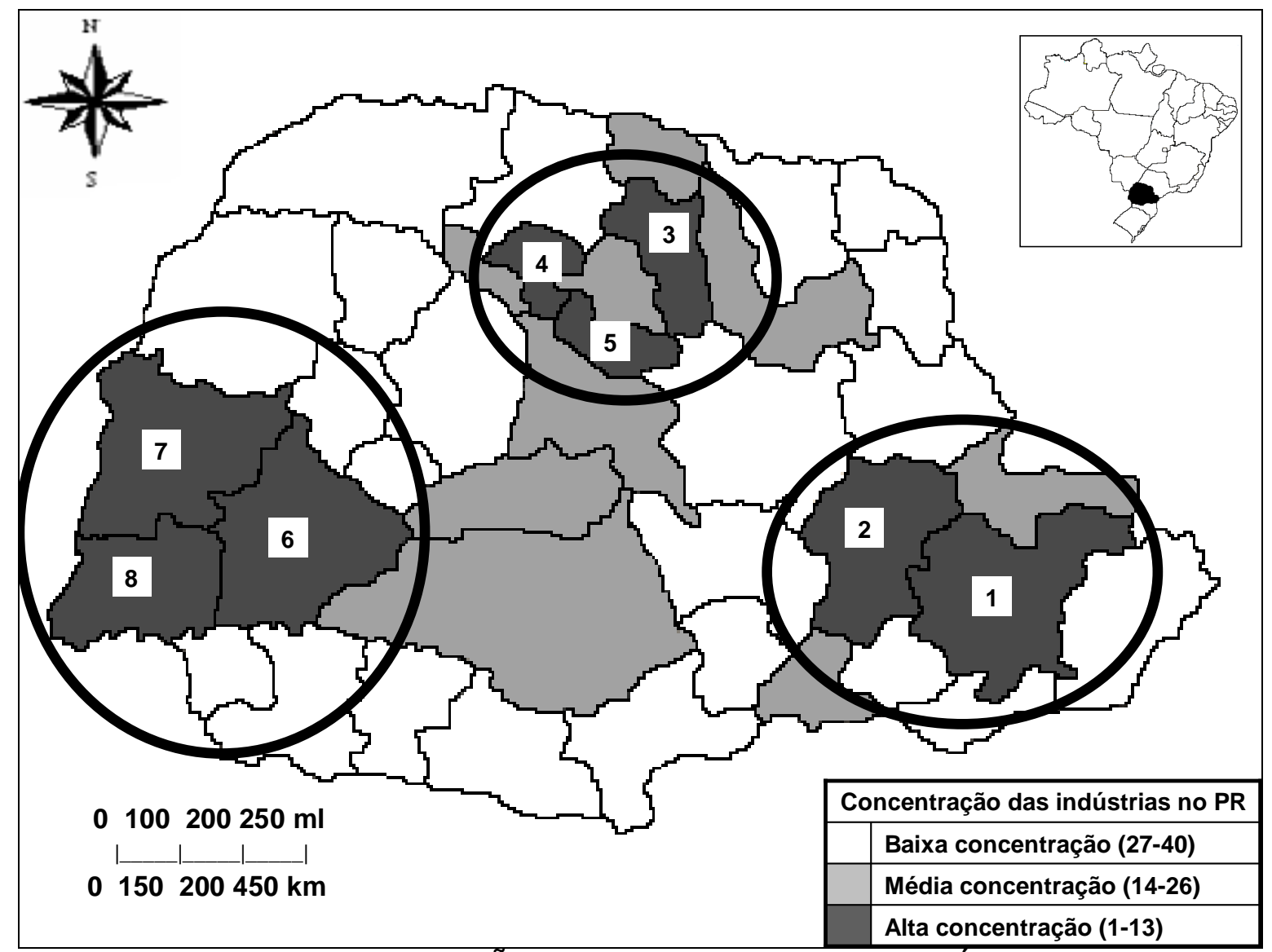

MAPA 1 - DESCONCENTRAÇÃO INDUSTRIAL NO PARANÁ ENTRE OS ANOS 1991 E 2000

FONTE: DADOS DA PESQUISA (2007)

No Estado de Santa Catarina percebe-se uma configuração mais homogênea do espaço, com destaque maior para as microrregiões Blumenau, Joinville, Chapecó, Tubarão e Joaçaba que estão crescendo de forma ordenada no espaço, comparativamente aos Estados do Paraná e do Rio Grande do Sul.

No Estado do Rio Grande do Sul o rearranjo espacial aponta uma desconcentração da microrregião de Porto Alegre, porém, essa desconcentração alavanca as microrregiões ao redor desta e traça um corte radical entre o Oeste e o Leste gaúcho. Das 11 primeiras microrregiões que mais tiveram crescimento industrial no Rio Grande do Sul, todas estão ou próximas da microrregião de Porto Alegre ou estão localizadas no Leste do Estado gaúcho, demonstrados no mapa 2, como as microrregiões de Caxias(1), Porto Alegre(2), Gramado-Canela(3), LajeadoEstrela(4), Montenegro(5), São Jerônimo(6), Guaporé(7), Passo Fundo(8), Santa 
Cruz(9), Osório(10) e Erechim(11), aprofundando ainda mais a desigualdade existente no Estado.

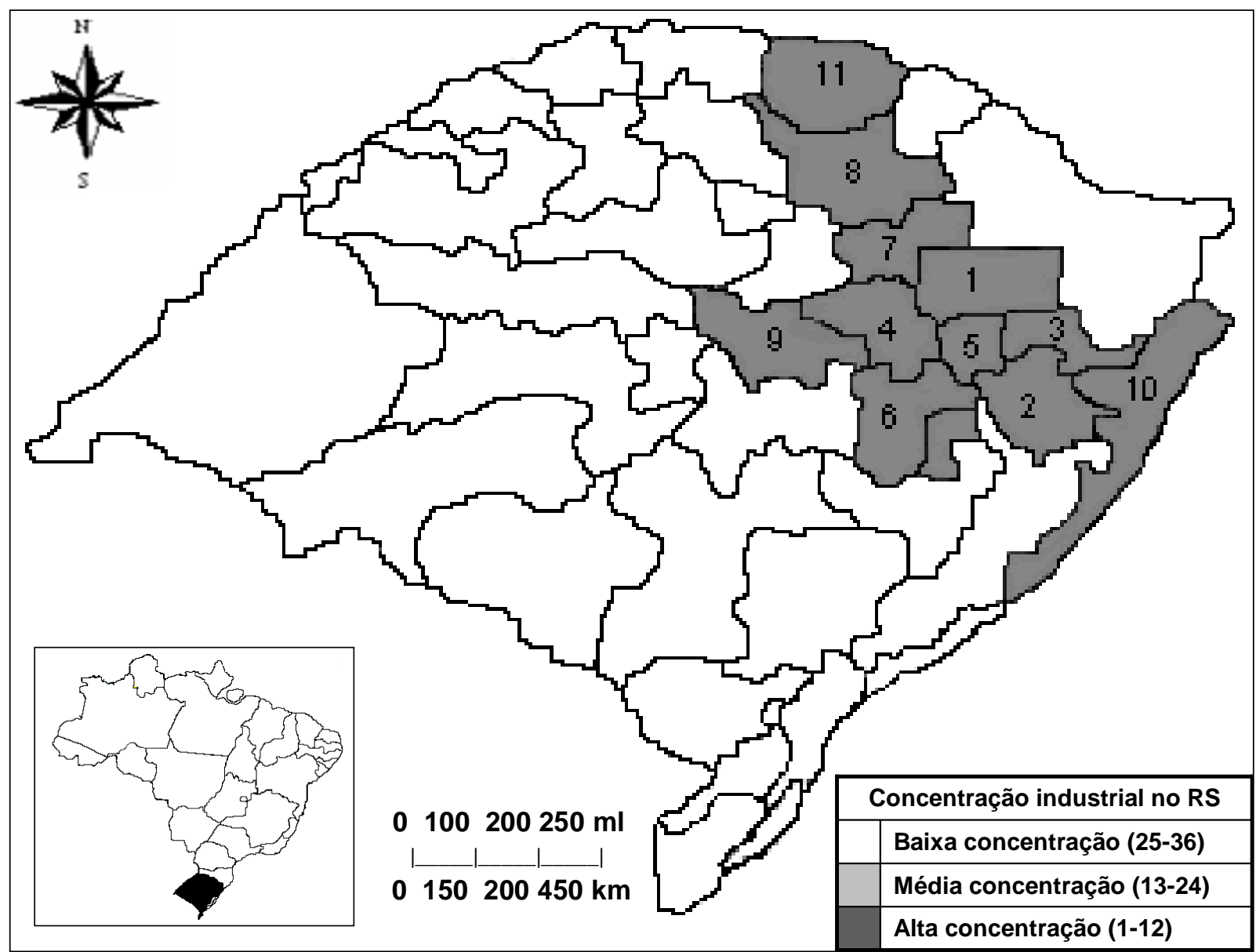

MAPA 2 - CONCENTRAÇÃO INDUSTRIAL NO RIO GRANDE DO SUL ENTRE OS ANOS 1991 E 2000

FONTE: DADOS DA PESQUISA (2007)

A desigualdade regional provoca sérias conseqüências, neste sentido, medidas de planejamento e desenvolvimento regional necessitam ser aplicadas como medidas emergenciais. Caberia a política de desenvolvimento regional incentivar a implantação de indústrias que estivessem adaptadas às particularidades regionais e se pensar num desenvolvimento regional sustentável, para não ocorrer um processo de inchaço populacional no Leste gaúcho e um esvaziamento no Oeste. No contexto das atividades de transformação no Rio Grande do Sul, esses resultados convergem com os estudos de Souza (2005), no qual o padrão de localização industrial do Estado orientava-se pela fonte de matérias-primas, em 
especial aquelas voltadas para o comércio exterior. $\mathrm{O}$ que exige um suporte em termos de infraestrutura de serviços e comércio capaz de lhe dar sustentação, estimulando a associação geográfica entre as atividades urbano-industriais ao longo do território.

\section{CONCLUSÃO}

Esse artigo analisou a polarização dos centros econômicos em detrimento do interior dos Estados sulinos, no final do século XX. Com a aplicação da Análise Fatorial pelo Método de Componente Principal, notaram-se duas tendências que reforçam a idéia da desconcentração industrial:

Primeiro, verificou-se que nos Estados da Região Sul do Brasil ocorreu desconcentração industrial no espaço da macrorregião, fortalecendo um a localização industrial de empresas mais adensadas em tecnologia (mecatrônica, matérias de transporte, material elétrico e química) entre as mesorregiões do Nordeste Riograndense, Norte Catarinense e Mesorregiões Metropolitanas, particularmente nas microrregiões de Curitiba, Joinville, Blumenau, Caxias do Sul e Porto Alegre. Segundo, houve o fortalecimento das mesorregiões do interior da macorregião Sul do Brasil na agroindústria. Ou seja, a Região Sul passou a vivenciar um processo de reestruturação do espaço econômico, com o surgimento de novas frentes industriais, principalmente no Oeste paranaense, destacando-se as microrregiões de Toledo, Cascavel e Foz do Iguaçu e no Centro-Norte do Paraná, em Apucarana. Já no Estado de Santa Catarina a distribuição industrial ocorre de maneira mais homogênea. No entanto, no Rio Grande do Sul a concentração industrial no Leste do Estado, o divide drasticamente em duas partes, a industrializada e a não industrializada. O rearranjo espacial da localização industrial no Rio Grande do Sul demonstra a desconcentração da microrregião de Porto Alegre em direção ao seu entorno e as microrregiões da mesorregião do Nordeste/RS, mantendo a posição significativa do corredor Porto Alegre-Caxias do Sul na formação do Produto Interno Bruto gaúcho.

Uma das alternativas para as microrregiões do Sul do Brasil seria o fortalecimento das atividades locais, em especial dos Arranjos Produtivos Locais (APLs). De um lado esses APLs podem atender as demandas regionais e de outro, 
à medida que incorporarem inovações e se qualificarem à atividades de exportação, poderão se tornar cada vez mais atividades motoras das economias regionais. $\mathrm{Ou}$ seja, os APLs surgem como uma estratégia de fortalecimento da base produtiva autônoma das microrregiões periféricas do Sul do Brasil que não são atrativas ao grande capital industrial. Paralelo a isso, sugere-se uma política coordenada de desenvolvimento local nos Estados da Região Sul do Brasil que fortaleça as aglomerações industriais localizadas no interior do território, oferecendo à elas infraestrutura, redes de transporte, energia, comunicação e bases para a inovação.

\section{REFERÊNCIAS}

AZZONI, C. R; CAPELATO, R. Ranking das regiões paulistas segundo potencial de mercado. Economia e Empresa. Campinas, v. 03, n. 03, p. 04-21, 1996.

AZZONI, C. R.; FERREIRA, D. Competitividade regional e reconcentração industrial: o futuro das desigualdades regionais no Brasil. São Paulo: mimeo, 1997.

DINIZ, C. C. A dinâmica regional recente da economia brasileira e suas perspectivas. Brasília: IPEA, 1995.

DINIZ, C. C.; CROCCO, M. A. Reestruturação produtiva e novos distritos industriais no Brasil. São Paulo: mimeo, 1994.

FERRERA DE LIMA, J. A. concepção do espaço econômico polarizado. Interações. Revista Internacional de Desenvolvimento Local, Campo Grande, v. 04, n. 07, p. $07-13$, set. 2003

FERRERA DE LIMA, J. et al. O padrão de localização e de difusão da mão-de-obra na Região Sul do Brasil. Ensaios FEE, Porto Alegre, v. 28, n. 01, p. 189-224, 2007.

FERRERA DE LIMA, J.; ALVES, L.; PIACENTI, C. A. O perfil locacional do emprego setorial no Brasil. Revista Econômica do Nordeste, Fortaleza, v. 39, n. 03, p. 482502, 2008.

FONSECA NETTO, H. Vers un nouveau découpage de l'espace brésilien. Revue Organisations et Territoires. Québec, v. 10, n. 02, p. 99-110, 2001.

FONSECA M. W.; PERES, A. F. O Paraná perante o processo de desconcentração industrial brasileiro. Ciências Sociais Aplicadas em Revista, Marechal Cândido Rondon, v. 02, n. 02, p. 09-28, 2002.

HOFFMANN, R. Componentes principais e análise fatorial. Piracicaba: DESR/ESALQ/USP, 1999. 
INSTITUTO BRASILEIRO DE GEOGRAFIA E ESTATÍSTICA (IBGE). Indicadores. 2007. Disponível em: <http://www.ibge.gov.br/home/estatistica>. Acesso em: 15 maio 2007.

KRUGMAN, P. Increasing returns and economic geography. Journal of Political Economy, Washington (DC), n. 99, p. 483-499, 1991.

MARTINE, G.; DINIZ, C. Concentração econômica e demográfica no Brasil: recente inversão do padrão histórico. Revista de Economia Política, São Paulo, v. 11, n. 03, p.121-135, 1991.

PACHECO, C. A. Novos padrões de localização industrial? Tendências recentes dos indicadores da produção e do investimento industrial. Brasília: IPEA, 1999.

PERROUX, F. A economia do século XX. Lisboa: Herber, 1967.

A idéia de progresso perante a ciência econômica do nosso tempo. Lisboa: Análise Social, 1964.

Dialogue des monopoles et des nations: équilibre ou dynamique des unités actives? Grenoble: Presses universitaires de Grenoble, 1982.

O conceito de pólo de crescimento. In. SCWARTZMANN, J. (org.) Economia regional e urbana: textos escolhidos. Belo Horizonte: CEDEPLAR, 1977. p. $145-156$.

RELAÇÃO ANUAL DE INFORMAÇÕES SOCIAIS (RAIS). 2007. Disponível em: $<$ http://www.rais.org.br>. Acesso em: 10 jun. 2007.

RIPPEL, R.; FERRERA DE LIMA, J. Pólos de crescimento econômico: Notas sobre o caso do Estado do Paraná. Revista Redes, Santa Cruz do Sul, v. 14, n. 01, p. 136-149, 2009.

RODRIGUEZ, D. A. Cenários de desenvolvimento regional. BNDES: mimeo, 1997.

RUIZ, R. M.; DOMINGUES, E. P. Corredores industriais na Região Sul. VIII Encontro de Economia da Região Sul, ANPEC SUL. Porto Alegre: ANPEC. Anais..., v. 01, n. 01, CD-ROM, 2005.

SCREMIN, M. A. A. método para a seleção do número de componentes principais com base na lógica difusa. 2003. 124f. Tese (Doutorado em Engenharia de Produção) - Universidade Federal de Santa Catarina, Florianópolis, 2003.

SOUZA, N. J. Polarização e despolarização industrial no Brasil e no Rio Grande do Sul. Análise Econômica, Porto Alegre, v. 08, n. 13, 1990. 
Estrutura espacial das atividades econômicas do Rio Grande do Sul, 1990/2000. Estudos do CEPE, Santa Cruz do Sul, n. 21, p. 91-116, jan./jun. 2005.

(Recebido em 03.07.2010. Aceito em 20.02.2011) 